\section{Interlocuções das associações de pacientes com doenças raras, indústria farmacêutica e Estado sob a reflexão da bioética de intervenção}

\section{Nascimento, Dalvina Benicio do}

Doutoranda da Cátedra UNESCO de Bioética da Universidade de Brasília. Programa Pós-graduação em Bioética - UNB. dalvinabn@gmail.com

\section{Monsores, Natan}

Observatório de Doenças Raras. Programa de Pós-graduação da Cátedra UNESCO de Bioética da Universidade de Brasília.

Palavras-chave: Bioética, associações de pacientes, doenças raras, Estado, indústria farmacêutica.

As pessoas com Doenças Raras (DR) diariamente enfrentam vários desafios relativos ao cuidado em saúde: enfretamento dos sintomas, dificuldades com diagnóstico e exames, falta de assistência multiprofissional e dificuldades no acesso aos medicamentos que necessitam. A baixa prevalência é aventada como pretexto para o desinteresse e o desconhecimento por parte de governos, do setor saúde, da indústria farmacêutica e da sociedade em geral. Mas estudos têm apontado o impacto social e sanitário destas doenças, que em conjunto, afetam cerca de $6 \%$ da população. $\mathrm{O}$ objetivo do presente estudo é discutir, fundamentado em preceitos bioéticos, quais são os conflitos que podem perpassar a interação entre associações de pacientes, indústria farmacêutica, academia e o Estado. Realizou-se pesquisa descritiva e exploratória cujos dados serão tratados e discutidos a partir dos marcos conceituais de abordagens latino-americanas da Bioética, que possibilitem avaliar o engajamento destes diferentes interlocutores no debate público sobre DR. Considerando que as poucas políticas de saúde são construídas com base nas práticas fundamentadas em evidências e com proposição utilitarista, e que há dinâmicas neoliberais na relação mercado-Estado que interferem fortemente na questão de acesso a tratamento, percebe-se que há fatores epistemológicos e políticos que dificultam a garantia de cuidados em saúde para pacientes com DR. Nesse cenário, as associações de pacientes constituem um aparelho social de apoio importante, garantindo advocacia em saúde e divulgação da realidade vivenciada pelos pacientes e suas famílias, envidando esforços para amenizar a realidade de exclusão que invade suas vidas. A esse respeito, é preciso considerar criticamente que essas associações podem receber apoio do Estado ou ainda estar sob financiamento ou apoio da Indústria, o que estabelece um conflito de interesses na mobilização da opinião pública. Quanto a essas inter-relações, Garrafa e Porto (2005) explicitam que a "sociedade de mercado", supostamente em busca de desenvolvimento é capaz de alterar o "pacto social", para um instrumento de comprar e vender, suprimir "valores humanos, produzindo desigualdades econômicas e sociais entre indivíduos, grupos e segmentos no âmbito interno das nações, além de flagrante assimetria política entre elas". Ao considerar o impacto das questões de saúde, Tealdi (2008) afirma que distintos graus de doenças causam diversos graus de vulnerabilidade, sendo o papel da bioética preocupar se com a "vulnerabilidade e toda forma de vulneração do ser humano". A isso, acrescenta-se o que a BI propõe que "a ação social politicamente comprometida é aquela [capaz]de transformar a práxis social [e] exigir persistência, preparo acadêmico, militância programática e coerência histórica”. Essa definição representa fielmente a luta dos familiares de pacientes com DR, de associações de pacientes e daqueles que são comprometidos na busca para transformar a realidade dessas pessoas. Concluindo, pondera-se que tanto no modo de construção das políticas públicas pelo Estado, como nas dinâmicas relativas a pesquisa clínica e comercialização de medicamentos, o jogo de interesses pode produzir a marginalização dos pacientes com DR. O provimento de assistência integral ao paciente com DR precisa ser francamente debatido pela sociedade, a fim de não se configurarem práticas que violem direitos humanos.

Agradecimento: Ao PPG em Bioética da UnB, a CAPES pela bolsa de estudo, ao meu orientador prof. Natan Monsores pela paciência, e aos professores.

[1] Sartori Junior D et al. Judicialização do acesso ao tratamento de doenças genéticas raras: a doença de Fabry no Rio Grande do Sul. Ciência \& Saúde Coletiva, 2012; 17(10):2717-2728.

[2] Portugal S. Para um começo de reflexão sobre o cuidado das doenças raras. In: Faria R. Dia mundial das doenças raras. Câmara dos Deputados, Brasília; 2013.

[3] Barbosa R.L.; Portugal S. O Associativismo faz bem à saúde? O caso das doenças raras. Cien Saude Colet 2018, 23(2): 417-430.

[4] Tealdi JC (dir). Diccionario latinoamericano de bioética. Bogotá:Universidad Nacional de Colombia; 2008:182-252.

[5] Porto D, Garrafa V. Bioética de Intervenção: considerações sobre a economia de mercado. Bioética (CFM), 2005, 13 (1): 111-123. 